Federal Reserve Bank of Minneapolis

Research Department Staff Report 98/JV

\title{
Coordination of Fiscal Policies in a World Economy
}

\author{
Patrick J. Kehoe* \\ Federal Reserve Bank of Minneapolis \\ and University of Minnesota
}

\begin{abstract}
This paper provides a simple counterexample to the standard belief that in a world economy in which all countries are small, strategic interactions between policymakers are trivial and thus cooperative and noncooperative government policies coincide. It is well known that this holds for tariff policies. However, this paper demonstrates the result does not apply to government policies generally. Indeed, this paper presents a simple counterexample for the case of fiscal policy. In addition, the paper analyzes how optimally coordinated fiscal policies differ from noncooperative policies. It finds that, relative to optimally coordinated levels, noncooperative government spending can be too high or too low, depending on the sign of a transmission effect which captures the overall effect countries' actions have on each other.

*Andrew Abel, David Backus, Robert Hodrick, Paul Richardson, Thomas Sargent, and James Schmitz provided helpful comments. Edward Prescott provided valuable guidance at an early stage of this project. Kathy Rolfe provided useful editorial assistance. This project was undertaken in connection with Sloan Foundation Grant 85-4-3, called "Coordination of Macroeconomic Policies in Dynamic Open Economies." The views expressed herein are those of the author and not necessarily those of the Sloan Foundation, the Federal Reserve Bank of Minneapolis, or the Federal Reserve System.
\end{abstract}


In an integrated world economy, the effects of one government's macropolicy may depend on other governments' policies. When governments have conflicting objectives, this leads to strategic interactions among governments when setting policy. The standard intuition is that as each country's economy becomes small relative to the world economy these strategic interactions become trivial and thus cooperative and noncooperative policies should converge. This intuition is correct for tariff policy; however, this paper shows it is not correct for government policy generally. Indeed, this paper presents a simple example in which as each country's economy becomes small the cooperative and noncooperative government policies diverge.

The paper also analyzes how optimally coordinated (or cooperative) policies differ from noncooperative policies. It finds that, relative to optimally coordinated levels, noncooperative government spending and taxes can be either too high or too low, depending on the sign of a transmission effect which captures the overall effect countries' actions have on each other.

For the analysis, a model is constructed to meet three requirements. First, since policy is analyzed across regimes, the decision mies of agents should be derived at a primitive enough level so that they will necessarily be invariant across regimes. Second, the model should capture some of the intertemporal tradeoffs between current and future effects (loosely, "short-run" and "long-run" effects) arising from changes in the level of government spending. Third, the model should be tractable, in the sense that its equilibria can be explicitly calculated as a function of the underlying parameters.

The simplest model that meets these requirements is a multicountry parametric version of Diamond's (1965) life-cycle growth model modified to 
include public goods. Each country's government sets its spending and taxes in order to maximize the welfare of its residents. To isolate the forces behind the main result, I abstracted from those features that would simply complicate the example. In particular, I excluded distortionary taxes and externalities (except, of course, for the public goods--which may be thought of as a limiting type of externality). Also, to prevent confusion that this result is driven by a time inconsistency problem, the governments are not permitted to tax capital or to issue debt. 1/ The fact that such a counterexample can be constructed for a rather standard parametric case (CobbDouglass utility and production functions) without resorting to any of these other features serves to make the example more striking.

In the paper, government policies are compared under two regimes: a sequential Nash equilibrium (as in Prescott and Townsend 1980) and a coordinated equilibrium. To compute these equilibria, a recursive algorithm of Levhari and Mirman (1980) is used. The algebra involved in the calculations is somewhat tedious and is therefore relegated to Appendix A. Since the paper devotes much attention to the steady state properties of the resulting equilibria, one might think that a type of steady state game could instead be defined. Since it is well known, however, that in general such a game does not imply sequentially rational decisionmaking, the possibility is not explored here (see Green 1977).

Basically, the logic behind the main result--that gaming problems get worse as the number of countries increases--is as follows. For a fixed number of countries, an increase in government spending by one country directly affects that country through the public goods channel. By crowding out the world capital stock, the increased spending also indirectly affects all 
countries. As the number of countries increases, the direct effect stays constant while the indirect effect diminishes. This distinction between the direct and indirect effects is crucial to the result.

The second result--that relative to the coordinated levels, the noncooperative levels of spending can be too high or too low--is driven by the tension between the current and future effects on welfare of an increase in government spending. Since current generations benefit at the expense of future generations, the result depends crucially on the number of such future generations left in the game. In particular, the longer the game is, the more likely that noncooperative spending levels are too high.

Recently a good deal of work has used game theory to examine macropolicy in a world economy. While this paper focuses on fiscal policy, most of the literature focuses on monetary policy. Hamada (1976) wrote one of the first papers in this area. Cooper (1985) provides references to subsequent work. Within this literature on monetary policy, the closest relatives to the current paper are Miller and Wallace (1985) and Sebastian (1985). Both of these papers, however, analyze the type of steady state game referred to above.

This paper is organized as follows: Section I describes the environment; Section II analyzes single-country equilibrium; Sections III, IV, and $\mathrm{V}$ analyze two-country equilibrium; Section VI analyzes multicountry equilibrium; and Section VII provides the conclusion.

\section{The World Economy}

Consider a one-good world economy consisting of two countries. Each country is populated by overlapping generations of two-period-lived consumers as well as firms and a government. The countries are identical except for the policy of the governments. 
At time $t$, country $i$ is populated with $L$ young consumers and $L$ old consumers. Since there is no growth in population, there is no loss in generality if $I$ is set equal to 1. Each consumer of country $i$ is endowed with one unit of labor when young and none when old. The agent supplies this unit of labor inelastically and receives wages $w_{i t}$ out of which the agent consumes $y_{i t}$, saves $s_{i t}$, and pays taxes $\theta_{i t} W_{i t}$, all measured in units of the time $t$ good. (Notice that since labor is supplied inelastically, the tax does not distort the labor supply decision.) The agent can save by renting some goods to the firm to be used as capital. An agent who saves $s_{i t}$ at $t$ receives $\left(1+r_{i, t+1}\right) s_{i t}$ at time $t+1$, which the agent then spends entirely on consumption when old, $z_{i, t+1}$. Agents of country $i$ born at time $t$ also each receive $g_{\text {it }}$ units of government services over their lifetime.

Consumers of country $i$ are assumed to value their individual consumption stream $\left(y_{i t}, z_{i, t+1}, g_{i t}\right)$ according to

$$
u\left(y_{i t}, z_{i, t+1}, g_{i t}\right)=\ln y_{i t}+\delta \ln z_{i, t+1}+\lambda \ln g_{i t} .
$$

Confronted with prices $\left(w_{i t}, r_{i, t+1}\right)$ and a tax rate $\theta_{i t}$ on wages and provided with government services $g_{i t}$, a consumer in country $i$ solves this problem:

$$
\max _{\left\{s_{i t}\right\}} \text { In } y_{i t}+\delta \ln z_{i, t+1}+\lambda \ln g_{i t}
$$

subject to

$$
\begin{aligned}
& y_{i t}=\left(1-\theta_{i t}\right) w_{i t}-s_{i t} \\
& z_{i, t+1}=\left(1+r_{i, t+1}\right) s_{i t} \\
& y_{i t}, z_{i, t+1}>0 .
\end{aligned}
$$


Notice that consumers are free to choose the level of private consumption $\left(y_{i t}, z_{i, t+1}\right)$ they desire (subject, of course, to their budget constraint), but they are not free to choose the level of consumption of public services $g_{i t}$. Here $g_{i t}$ is the flow of services from a public good supplied by country $i$ that benefits only country $i$ residents. The government is assumed to transform units of the private good into units of the public good at a oneto-one rate. The assumption that consumers benefit from government services only when young simplifies computations and, as Appendix B shows, has no qualitative effect on the results.

Solving (1) for $s_{\text {it }}$ yields the optimal savings policy:

$$
s_{i t}=\delta\left(1-\theta_{i t}\right) w_{i t} /(1+\delta)
$$

The firm in country $i$ rents $K_{i t}$ units of the one good from joung savers at time $t-1$ for a promise to pay $\left(1+r_{i t}\right) K_{i t}$ units of goods at $t$. The firm also rents labor $I_{i t}^{D}$ at time $t$ for current pay of $w_{i t} L_{i t}^{D}$. The firm then combines the capital and labor to produce a total output, inclusive of undepreciated cepital, of $K_{i t}^{\alpha}\left(I_{i t}^{D}\right)^{1-\alpha}$. The firm solves this problem:

$$
\max _{\left\{K_{i t}, L_{i t}^{D}\right\}} K_{i t}^{\alpha}\left(L_{i t}^{D}\right)^{1-\alpha}-w_{i t} I_{i t}^{D}-\left(1+r_{i t}\right) K_{i t} .
$$

The first-order conditions for the firm in per capita form are

$$
\begin{aligned}
& \alpha k_{i t}^{\alpha-1}=1+r_{i t} \\
& (1-\alpha) k_{i t}^{\alpha}=w_{i t}
\end{aligned}
$$

where $k_{i t}=K_{i t} / L_{i t}^{D}$. Later analysis will be helped by defining functions $w(\cdot)$ and $r(\cdot)$ by $1+r(k)=\alpha k^{\alpha-1}$ and $w(k)=(1-\alpha) k^{\alpha}$. 
The government of country $i$ collects taxes $\theta_{i t} w_{i t}$ from its young residents at $t$ which it uses to finance government spending $g_{i t}$ yielding this budget constraint:

$$
g_{i t}=\theta_{i t} w_{i t}
$$

A fiscal policy of government i can be completely described by sequences of government spending and tax rates $\left\{g_{i t}, \theta_{i t}\right\}$ that satisfy (6). Notice that the model does not include bonds. Thus, the government's budget constraint is always balanced, and consumers save by renting capital to firms. This assumption, together with the functional form assumptions for the utility and production functions, will ensure the existence of closed form decision rules for private agents and, in later analysis, for the government. This will permit an explicit and complete characterization of the resulting equilibria as a function of the parameters of these functions. 2/

II. Equilibrium in a Closed Economy

For comparison with later results, a study of the behavior of a closed economy equilibrium in country $i$ will be useful. In a closed economy equilibrium, three markets operate in country $i$ at period $t$ : a financial market, a goods market, and a labor market. In the financial market, time $t$ goods are exchanged for claims to time $t+1$ goods. The young in country $i$ supply $s_{i t}$ while firms demand $k_{i, t+1}$. Equilibrium requires

$$
s_{i t}=k_{i, t+1}
$$

for each t. Clearly, equilibrium in the financial market implies equilibrium in the current goods market. Equilibrium in the labor market requires $I_{i t}^{D}=1$ for each $t$. 
Given a fiscal policy $\left\{g_{i t}, \theta_{i t}\right\}$, a closed economy equilibrium for country $i$ is a sequence of prices $\left\{w_{i t}, r_{i t}\right\}$ and allocations $\left[s_{i t}, k_{i t}\right\}$ such that $s_{i t}$ solves the consumer's problem, $k_{i t}$ solves the firm's problem, $s_{i t}$ and $k_{i t}$ satisfy financial market-clearing $(7)$, and at these prices $\left\{g_{i t}, \theta_{i t}\right\}$ satisfies the government budget constraint ( 6$)$. Note that, given $s_{i t}$ and $\theta_{i t}$ and prices $w_{i t}, r_{i, t+1}$, we can determine $y_{i t}$ and $z_{i, t+1}$ from the budget constraints in (1).

The state of the economy at $t$ can be summarized by the capital stock inherited from the previous period, $k_{i t}$. Substituting the expression for wages in (5) into (2) and using the financial market equilibrium condition (7) yields the equilibrium law of motion for capital, namely,

$$
k_{i, t+1}=h\left(k_{i t}, \theta_{i t}\right)
$$

where $h\left(k_{i t}, \theta_{i t}\right)=\delta(1+\delta)^{-1}(1-\alpha)\left(1-\theta_{i t}\right) k_{i t}^{\alpha}$.

Consider the steady-state properties of this system. A steady state of a closed economy equilibrium in country $i$ is a pair $\left(\theta_{i}, k_{i}\right)$ such that $k_{i}$ is the steady-state capital stock corresponding to a constant tax rate $\theta_{i}$; that is, given $\theta_{i}, k_{i}$ solves $k_{i}=h\left(k_{i}, \theta_{i}\right)$. For our example we can explicitly solve for the steady-state capital stock as a function of the tax rate:

$$
k_{i}=k\left(\theta_{i}\right)=A\left(1-\theta_{i}\right)^{1 /(1-\alpha)}
$$

where $A=\left[\delta(1+\delta)^{-1}(1-\alpha)\right]^{1 /(1-\alpha)}$, which is a positive constant. By construction, for each tax rate there is a unique steady-state capital stock. Inspection of the law of motion of capital reveals that the model possesses a simple turnpike property: given a constant tax sequence, $\theta_{i}$, the capital stock converges (at an exponential rate) to the steady-state capital stock $k\left(\theta_{i}\right)$. Thus, for each tax rate there is a unique, globally stable steady state. 
Figures 1 and 2 characterize the steady state graphically. The steady-state capital stock varies with the tax rate as in Figure 1. 3/ Government revenues are given by $\tau\left(\theta_{i}\right)=\theta_{i} w\left[k\left(\theta_{i}\right)\right]$, which for the example can be written

$$
\tau\left(\theta_{i}\right)=(1-\alpha) A^{\alpha} \theta_{i}\left(1-\theta_{i}\right)^{\alpha /(1-\alpha)} .
$$

Revenues vary with the tax rate as in Figure 2. 4/ It is straightforward to show that, for a closed economy, tax revenues are maximized by setting $\theta=1$ a. The difference between the steady-state properties of this single-country equilibrium and those of the many-country equilibrium will help clarify some of the later results.

III. Equilibrium in a Two-Country World

In a world equilibrium, domestic agents can save by holding either domestic or foreign capital and the individual countries are integrated. In this integrated world economy, two world markets operate at $t$ : a financial market and a current goods market. Equilibrium in the financial market requires

$$
s_{1 t}+s_{2 t}=k_{1, t+1}+k_{2, t+1}
$$

for each t. This clearly implies equilibrium in the current goods market. Each country also has a domestic market for immobile labor. Equilibrium in these markets requires $L_{i t}^{D}=1$ for $i=1,2$ for each $t$.

World capital mobility implies that the rates of return on capital are equalized across countries; that is, $r_{1 t}=r_{2 t}=r_{t}$ for each $t$. Since capital-labor ratios and wage rates are monotonic functions of the interest 
rate, this implies the equality of both capital-labor ratios and wage rates across countries; $k_{1 t}=k_{2 t}=k_{t}$ and $w_{1 t}=w_{2 t}=w_{t} \cdot$

Given a set of fiscal policies $\left\{g_{1} t, \theta_{1 t}\right\}$ and $\left\{g_{2 t}, \theta_{2 t}\right\}$, a world twocountry equilibrium is a sequence of prices $\left\{w_{t}, r_{t}\right\}$ and allocations $\left\{s_{1 t}, s_{2 t}, k_{t}\right\}$ such that $s_{i t}$ solves consumer i's problem; $k_{t}$ solves the firm's problem; $s_{1 t}, s_{2 t}$, and $k_{t+1}$ satisfy world financial market equilibrium; and at these prices $\left\{g_{1 t}, \theta_{1 t}\right\}$ and $\left\{g_{2 t}, \theta_{2 t}\right\}$ satisfy the government budget constraints.

Again, note that given $s_{i t}$ and $\theta_{i t}$ and prices $w_{t}$ and $r_{t+1}$ consumption $y_{i t}$ and $z_{i, t+1}$ can be determined from the budget constraints in ( 1 ). The world equilibrium can be summarized by an equilibrium law of motion for the world capital-labor ratio, a sequence of tax rates for each country, optimal policy functions for each country's consumers, and a government spending policy for each country. The state of the world economy at $t$ can be summarized by the inherited world capital stock $k_{t}$. Current wages and interest rates in both countries are given by $w\left(k_{t}\right)$ and $r\left(k_{t}\right)$. Substituting the expression for wages into (2) and using the financial market equilibrium condition (10) yields the equilibrium law of motion for capital, namely,

$$
k_{t+1}=h\left(k_{t}, \theta_{1 t}, \theta_{2 t}\right)=\delta(1+\delta)^{-1}(1-\alpha)\left(1-\theta_{\text {mt }}\right) k_{t}^{\alpha}
$$

where $\theta_{\mathrm{mt}}=\left(\theta_{1}+\theta_{2 t}\right) / 2$ is the world mean tax rate at $t$. Notice that the law of motion for capital depends on individual tax rates only through their mean. In fact, comparison of (11) and (8) reveals that $h\left(k_{t}, \theta_{1 t}, \theta_{2 t}\right)=$ $h\left(k_{t}, \theta_{m t}\right)$; that is, the law of motion for capital in a world economy is identical to that of a closed economy in which tax rates are set equal to the mean world tax rate. This feature arises, in part, from the fact that the utility functions in (1) are identical and intertemporally homothetic. 
The state of a consumer of country $i$ at time $t$ can be summarized by the world capital stock $k_{t}$ together with current taxes on labor in both countries, $\theta_{1 t}$ and $\theta_{2 t}$. The optimal policies for consumption can be expressed as a function of these state variables. For country 1 consumers,

$$
\begin{aligned}
& y\left(k_{t}, \theta_{1 t}, \theta_{2 t}\right)=(1+\delta)^{-1}(1-\alpha)\left(1-\theta_{1 t}\right) k_{t}^{\alpha} \\
& z\left(k_{t}, \theta_{1 t}, \theta_{2 t}\right)=\alpha(1-\alpha) \delta(1+\delta)^{-1}\left(1-\theta_{1 t}\right) k_{t}^{\alpha} h\left(k_{t}, \theta_{1 t}, \theta_{2 t}\right)^{\alpha-1} .
\end{aligned}
$$

The current tax on labor in country 2 is a state variable for consumers in country 1 because it affects the next period's capital stock which affects the interest rate they face. The policy functions for country 2 consumers are the functions in (12) and (13) with the tax rates reversed. Government spending in country 1 can be written

$$
g\left(k_{t}, \theta_{1 t}\right)=(1-\alpha) \theta_{1 t} k_{t}^{\alpha}
$$

Then, given any initial capital stocks, (11)-(14) together with their counterparts for country 2 are a set of nonlinear difference equations that completely characterize the equilibrium for any sequence of tax rates, $\left\{\theta_{1 t}, \theta_{2 t}\right\}$. A steady state of the world economy is a triple $\left\{k_{1}, \theta_{1}, \theta_{2}\right\}$, where $k$ is the world capital stock corresponding to constant tax rates $\theta_{1}$ and $\theta_{2}$. That is, given $\theta_{1}$ and $\theta_{2}, k$ solves $k=h\left(k, \theta_{1}, \theta_{2}\right)$. For our example, the steady-state capital stock can be written as a function of both countries' tax rates--say, $\mathrm{k}\left(\theta_{1}, \theta_{2}\right)$ where

$$
k\left(\theta_{1}, \theta_{2}\right)=A\left(1-\theta_{m}\right)^{1 /(1-\alpha)} .
$$


Equations (11) and (15) make it obvious that there is a unique, globally stable steady state for each pair of tax rates. In particular, notice that the steady state is independent of the relative size of the initial capital stocks. Comparison of (15) and (9) reveals that $k\left(\theta_{1}, \theta_{2}\right)=k\left(\theta_{m}\right)$; that is, the steady-state capital stock of the world economy is the same as that for a closed economy that sets its tax rate equal to the world mean tax rate.

Figures 3 and 4 characterize the world steady state graphically. The world capital stock varies with country 1 's tax rate as in Figure 3 . 5/

Included in Figure 3 for comparison is a dashed line depicting how the capital stock would vary with the tax rate $\theta_{1}$ if the economy were closed, $k\left(\theta_{1}\right)$ (which was graphed in Figure 1). Notice that a given change in country 1's tax rate produces a smaller change in the capital-labor ratio in a twocountry equilibrium than it does in a closed economy equilibrium. The reason is clear: in a two-country equilibrium the impact of country 1 's tax change on the world capital stock is diluted by the presence of the savings demand of country 2 's consumers.

Government revenues in country 1 in an integrated world are given by $\tau\left(\theta_{1}, \theta_{2}\right)=\theta_{1} w\left[k\left(\theta_{1}, \theta_{2}\right)\right]$, which for the example can be written

$$
\tau\left(\theta_{1}, \theta_{2}\right)=(1-\alpha) A^{\alpha} \theta_{1}\left(1-\theta_{m}\right)^{\alpha /(1-\alpha)} \text {. }
$$

Revenues to country 1 vary with its tax rate as in Figure 4. 6/ Clearly, country 1 's revenues depend on the tax rate that country 2 sets.

Since the world capital labor ratio depends only on mean world tax rate the revenue country 1 generates from a given tax rate $\theta_{1}$ is larger (smaller) in an integrated world than in a closed economy world if country 1 's tax rate is higher (lower) than country 2's tax rate. For a given country 2 
tax rate $\theta_{2}$, government revenues in country 1 are maximized by setting $\theta_{1}$ such that $\theta_{1}=2(1-\alpha)\left(1-\theta_{2} / 2\right)$.

IV. Noncooperative Fiscal Policies

In the last section, the policies of the governments were considered to be arbitrary. In this section, policies are considered to be outcomes of a noncooperative game. Initially, suppose that instead of two infinitely lived governments there are two infinite sequences of one-period-lived governments. In this and future sections, we will assume this. The assumption may be understood in two ways. It can be interpreted literally; that is, each government is actually an infinite sequence of one-period-lived governments. Or it can be interpreted as an intuitive way of modeling one infinitely lived government that acts sequentially. Now suppose the government of country $i$ at time $t$ is concermed not only with the welfare of current consumers in $i$ but also with the welfare of all future consumers in $i$. In particular, let this government's objective function be a weighted average of the utility functions of country $i$ consumers from generation $t$ onward. Let the weight assigned to generation $t+k$ be $\beta^{k}$.

Let the government of country 1 at time $t$ take as given the current state of the world economy and the actions of the current government of country 2 , and let it assume that the current actions of the consumers are determined according to (12) and (13). Since the objective function of this goverament depends on future welfare, we must specify both how it believes future consumers and governments will act and how it believes the state of the econony will evolve. Let the current government of country 1 believe that the future actions of consumers are determined according to (12) and (13), the future strategies of governments 1 and 2 are Nash equilibrium strategies, and 
the state of the economy evolves according to (11). Let the government of country 2 at time $t$ act symmetrically.

We will define and calculate a Nash equilibrium for an infinite horizon game by considering a sequence of finite horizon games. The limits of the equilibria for the finite horizon games are defined to be equilibria for the infinite horizon game. Initially, let the economy start at tine 0 and end at time T. There are several ways to end the economy, each of which will yield the same limiting policy and value functions. The most convenient way is to assume that the last generation, generation $T$, lives for only the young period of life. Obviously, for this last generation, consuming all net labor incone when young is optimal.

Consider a sequence of problems for the government. For brevity, call the government of country $i$ at time $t$ the government it. Let $R_{i t}\left(k, \theta_{1}, \theta_{2}\right)$ denote the objective function of government it. For the final government of country 1 ,

$$
\mathrm{R}_{1 \mathrm{~T}}\left(\mathrm{k}, \theta_{1}, \theta_{2}\right)=\ln \mathrm{y}+\lambda \ln \mathrm{g}
$$

where $y=\left(1-\theta_{1}\right) w(k)$ and $g=\theta_{1} w(k)$. Since there are no generations after $T$, the objective function of the final government depends only on the welfare of this last generation. This feature, together with the fact that the last generation lives only one period, implies that the final government's objective function does not depend on country 2's tax rate. For all governments of country 1 at $t<T$,

$$
R_{1 t}\left(k, \theta_{1}, \theta_{2}\right)=U\left(k, \theta_{1}, \theta_{2}\right)+\beta V_{1, t+1}\left[h\left(k, \theta_{1}, \theta_{2}\right)\right]
$$


where $U\left(k, \theta_{1}, \theta_{2}\right)=u\left[y\left(k, \theta_{1}, \theta_{2}\right), z\left(k, \theta_{1}, \theta_{2}\right), g\left(k, \theta_{1}\right)\right]$, which is the value of the current generation's utility given that it faces state variables $\left(k, \theta_{1}, \theta_{2}\right)$ and acts optimally. $V_{i, t+1}\left(k^{\prime}\right)$ denotes the discounted value of the utilities of country $i$ residents from generation $t+1$ to generation $T$, given inherited capital stock $k^{\prime}$ and given that all future governments play their Nash equilibrium strategies. The objective function of such a government is just the latility of the current generation plus the discounted value of future generations' utilities. The objective functions of country 2 are the same as for country 1 except that the subscripts are reversed and the superscripts are changed from 1 to 2 .

Let $\theta_{1 t}(\cdot)$ and $\theta_{2 t}(\cdot)$ respectively denote the strategies of governments 1 and 2 at time t. Define a Nash equilibrium at stage t to be a pair of strategies $\left\{\theta_{1 t}^{*}(\cdot), \theta_{2 t}^{*}(\cdot)\right\}$ that satisfy these conditions:

$$
\begin{aligned}
& \theta_{1 t}^{*}(\cdot) \text { solves } \max _{\theta_{1}} R_{1 t}\left[k, \theta_{1}, \theta_{2 t}^{*}(k)\right] . \\
& \theta_{2 t}^{*}(\cdot) \text { solves } \max _{\theta_{2}} R_{2 t}\left[k, \theta_{1 t}^{*}(k), \theta_{2}\right] .
\end{aligned}
$$

If only one pair of strategies satisfies $(16)$ and $(17)$, then $V_{1 t}(k)=$ $R_{1 t}\left[k, \theta_{1 t}^{*}(k), \theta_{2 t}^{*}(k)\right]$ and symmetrically for country 2 . Using the above, we can define an equilibrium for a game starting at $T-N$ and ending at $T$ : $A$ sequential Nash equilibrium I/ to the N-stage game is a collection of strategies $\left\{\theta_{1 t}^{*}(\cdot), \theta_{2 t}^{*}(\cdot) \mid t=T-n, \ldots, T\right\}$ such that for each $t\left\{\theta_{1 t}^{*}(\cdot), \theta_{2 t}^{*}(\cdot)\right\}$ satisfy (16) and (17).

In what follows we concentrate on symmetric equilibria. A symmetric Nash equilibrium at stage $t$ is a pair of policies $\left[\theta_{1 t}^{*}(\cdot), \theta_{2 t}^{*}(\cdot)\right\}$ that satisfy (16) and (17) and $\theta_{1 t}^{*}(k)=\theta_{2 t}^{*}(k)\left[\equiv \theta_{t}^{*}(k)\right]$. In this case, the maximized 
values of the objective functions $v_{i t}^{*}(k)$ are both equal to, say, $v_{t}^{*}(k)=$ $\mathrm{R}_{1 t}\left[\mathrm{k}_{t}, \theta_{t}^{*}(k), \theta_{t}^{*}(k)\right]$. Notice that the objective functions for the stage $t$ game are symmetric if each pair of future governments follows symmetric strategies. However, these functions are not necessarily symmetric otherwise.

For the parametric example, we can compute the symmetric equilibrium recursively by using an algorithm similar to the one Levhari and Mirman (1980) used. As Appendix A shows, the policy and value functions to the N-stage game are given by

$$
\begin{aligned}
& \theta_{T-N}^{*}(k)=\lambda /\left[1+\lambda+\delta-\left(q_{N} / 2\right)\right] \\
& V_{T-N}^{*}(k)=\left[\alpha \sum_{j=0}^{N}(\beta \alpha)^{j}-(\beta \alpha)^{N} \alpha^{2} \delta\right] \text { In } k+D_{T-N}
\end{aligned}
$$

where $q_{\mathbb{N}}=\Psi+(\beta \alpha)^{\mathbb{N}} \alpha \delta-n \sum_{j=1}^{N}(\beta \alpha)^{j}, \gamma=(1-\alpha) \delta$ and $n=1+\lambda+\alpha \delta$. As the horizon tends to infinity, the Nash equilibrium strategies and the value functions converge to $\theta^{*}(k)$ and $V^{*}(k)$, respectively:

$$
\begin{aligned}
& \lim _{N \rightarrow \infty} \theta_{T-N}^{*}(k)=\theta^{*}(k)=\lambda /[1+\lambda+\delta-(q / 2)] \\
& \lim _{N \rightarrow \infty} V_{T-N}^{*}(k)=V^{*}(k)=[\alpha N /(1-\beta \alpha)] \text { In } k+D
\end{aligned}
$$

where $q=\Psi-n \beta \alpha /(1-\beta \alpha)$. Now the pair $\{\theta(k), \theta(k)\}$ is defined to be the symmetric sequential Nash equilibrium for the infinite horizon game. We will compare these policy functions to optimally coordinated policy functions in the next section.

In this comparison it will be important to keep track of the transmission effect of a policy change, that is the effect a change in one country's tax rate has on the welfare of the other country. Here the sign of the 
transmission effect at stage $T-N$ is the same as the sign of $q_{N}$. To see this, consider the following variational question. Starting at the Nash equilibrium at stage $T-N$, how will a small increase in country 2 's tax rate affect country 1 's payoff? That is, what is $\partial R_{1, T-N}^{*} / \partial \theta_{2, T}, N$, where

$$
\begin{aligned}
& \mathrm{R}_{1, \mathrm{~T}-\mathrm{N}}^{*}\left[\mathrm{k}, \theta_{\mathrm{T}-\mathrm{N}}^{*}(\mathrm{k}), \theta_{\mathrm{T}-\mathrm{N}}^{*}(\mathrm{k})\right]= \\
& \quad \mathrm{U}\left[\mathrm{k}, \theta_{\mathrm{T}-\mathrm{N}}^{*}(\mathrm{k}), \theta_{\mathrm{T}-\mathrm{N}}^{*}(\mathrm{k})\right]+\beta \mathrm{V}_{\mathrm{T}-\mathrm{N}+1}\left(\mathrm{~h}\left[\mathrm{k}, \theta_{1, \mathrm{~T}-\mathrm{N}}^{*}(\mathrm{k}), \theta_{2, \mathrm{~T}-\mathrm{N}}^{*}(\mathrm{k})\right]\right) ?
\end{aligned}
$$

From (12), (13), (14), (18), and (19), it is straightforward to show that

$$
\partial R_{1, T-N}^{*} / \partial \theta_{2, T-N}=q_{N} / 2\left(1-\theta_{m, T-N}^{*}\right)
$$

So, clearly, an increase in country 2 's tax rates increases country $1^{\prime}$ 's welfare if $q_{\mathbb{N}}$ is positive and decreases it if $q_{\mathbb{N}}$ is negative. The term $q_{\mathbb{N}}$ represents the sum of several effects. To investigate these, write country 1 's objective function as

$$
\begin{aligned}
R_{1, T-N}\left(k, \theta_{T-N}^{*}, \theta_{T-N}^{*}\right)= & U\left(k_{T-N}, \theta_{T-N}^{*}, \theta_{T-N}^{*}\right) \\
& +\sum_{J=1}^{N} \beta{ }^{J} U\left(k_{T-N+J}, \theta_{T-N+J}^{*}, \theta_{T-N+J}^{*}\right) .
\end{aligned}
$$

This leads to (in obvious notation)

$$
\begin{aligned}
& \frac{\partial R_{1}, T-N}{\partial \theta_{2}, T-N}=\frac{\partial U\left(\cdot \cdot_{T-N}\right)}{\partial \theta_{2}, T-N}+\sum_{J=1}^{N} \beta^{J} \frac{\partial U(\cdot T-N+J}{\left.\partial k_{T-N}\right)} \quad \frac{\partial k_{T}-N+J}{\partial k_{T-N+J-1}} \ldots \\
& \frac{\partial k_{\mathrm{T}-\mathrm{N}+2}}{\partial \mathrm{k}_{\mathrm{T}-\mathrm{N}+1}} \quad \frac{\partial \mathrm{k}_{\mathrm{T}-\mathrm{N}+1}}{\partial \theta_{2, \mathrm{~T}-\mathrm{N}}} \text {. }
\end{aligned}
$$

The first term on the right side is the impact of an increase in country 2 's tax rate on the current generation's welfare. The only way a current tax increase by country 2 affects the current generation, that of $T-N$, is by 
increasing the interest rate between the period $T-N$ and $T-N+1$. Since the young are net savers, this effect is positive. For our example, the current generation effect is

$$
\partial U\left({ }_{T-N}\right) / \partial \theta_{2, T-N}=\Psi / 2\left(1-\theta_{m, T-N}^{*}\right)>0
$$

The terms in the sumation of (25) are the cumulative effects on all future generations. A current tax change affects such generations through the capital stock. A current tax increase, for example, directly decreases next period's capital stock and indirectly decreases all future capital stocks with geometrically declining weights. For our example,

$$
\frac{\partial k_{T-N+J}}{\partial k_{T-N+J+1}} \cdots \frac{\partial k_{T-N+2}}{\partial k_{T-N+1}} \quad \frac{\partial k_{T-N+1}}{\partial \theta_{2, T-N}}=-\frac{\alpha^{J-1} k_{T-N+J}}{2\left(1-\theta_{m, T-N}^{*}\right)} .
$$

The effect of a smaller capital stock on any future generation $T-N+J$ (except for the last one) is

$$
\begin{aligned}
\partial U\left(\cdot_{T-N+J}\right) / \partial k_{T-N+J}= & \left\{\left[U_{J}\left(1-\pi_{1, T-N+J}\right)+U_{g} \pi_{1, T-N+J}\right] \partial w_{T-N+J} / \partial k_{T-N+J}\right\} \\
& +\left\{\left[U_{z} s_{T-N+J}\right] \partial r_{T-N+J} / \partial k_{T-N+J}\right\} .
\end{aligned}
$$

For the example we can write this as

$$
\begin{aligned}
\partial U\left(\cdot_{T-N+J}\right) / \partial k_{T-N+J} & =\left[\alpha(1+\delta+\lambda) / k_{T-N+J}\right]-\left[\alpha \delta(1-\alpha) / k_{T-N+J}\right] \\
& =\alpha \eta / k_{T-N+J^{*}}
\end{aligned}
$$

The first term in (28) is a wage effect; a smaller capital stock leads to reduced wages and government spending and hence lower utility. The second term is an interest rate effect; a smaller capital stock leads to higher interest rates and hence higher utility, since the young are net savers. For 
the example the wage effect dominates the interest rate effect, and thus a lower capital stock reduces the utility of these future generations. For the last generation, the wage effect is simply $\alpha(1+\lambda) / k_{T}$ and the interest rate effect is, of course, zero. Using the definition of $n$ we can write the total effect on the last generation as

$$
\partial U\left(\cdot_{T}\right) / \partial k_{T}=\left(\alpha \eta-\alpha^{2} \delta\right) / k_{T} \cdot
$$

Using (25)-(30) we can write

$$
\frac{\partial R_{1}, T-N}{\partial \theta_{2, T}-N}=\frac{1}{2\left(1-\theta_{m, T-N}\right)}\left[\Psi-\eta \sum_{J=1}^{N}(\beta \alpha)^{J}+(\beta \alpha)^{N} \alpha \delta\right]
$$

which, from the definition of $q_{N}$, is just (23). In summary, higher taxes in country 2 have a positive effect on the current generation and negative effects on all future generations.

V. Coordinated Fiscal Policies

In the last section, the fiscal policies of the governments were set noncooperatively. Suppose instead the governments have some way of coordinating fiscal policies. (Of course, the structure of underlying institutions will determine if coordination is feasible. Here we simply characterize coordinated policies assuming it is.)

To solve for the optimal coordinated policy, consider a world planner who sets fiscal policies in both countries to maximize a world objective function. Suppose this world planner is actually an infinite sequence of oneperiod-lived planners. The planner of time $t$ sets the time $t$ fiscal policies In the two countries so that they maximize the average of the two time $t$ governments' objective functions. This planner takes as given the current state and assumes that the actions of current and future consumers are deter- 
mined according to (12) and (13), the actions of future planners are optimal given the future state, and the state of the economy evolves according to (11)

We can define and calculate the sequence of planners' problems recursively. Consider the same setup as in the last section. The objective function of the planner of time $T-N$ is

$$
R_{T-N}\left(k, \theta_{1}, \theta_{2}\right)=\left[R_{1, T-N}\left(k, \theta_{1}, \theta_{2}\right)+R_{2, T-N}\left(k, \theta_{1}, \theta_{2}\right)\right] / 2
$$

where the $R_{i, T-N}(\cdot)$ are as before and the $\hat{V}_{i, T-N}$ are the maximized value of utility given that all future planners act optimally given their future state. If each planner treats both countries symmetrically, then the optimal tax policy at stage $T$ is

$$
\hat{\theta}_{\mathrm{T}}(k)=\lambda /(1+\lambda) \text {. }
$$

For any stage before this--say, at $\mathrm{T}-\mathrm{N}--$

$$
\hat{\theta}_{\mathrm{T}-\mathrm{N}}(k)=\lambda /\left(1+\lambda+\delta-\mathrm{q}_{\mathrm{N}}\right)
$$

If $\hat{V}_{k}(k)$ is defined as $R_{T-N}\left[k, \hat{\theta}_{T-N}(k), \hat{\theta}_{T-N}(k)\right]$, then

$$
\hat{v}_{N}(k)=\left[\alpha \eta \sum_{j=1}^{N}(\beta \alpha)^{j}\right] \text { In } k+E_{N}
$$

where $\mathrm{E}_{\mathrm{N}}$ is a constant. As the horizon tends to infinity, the policy functions and the value functions converge to $\hat{\theta}(k)$ and $\hat{v}(k)$, respectively, where

$$
\begin{aligned}
& \lim _{\mathrm{N} \rightarrow \infty} \hat{\theta}_{\mathrm{N}}(\mathrm{k})=\hat{\theta}(\mathrm{k})=\lambda /[1+\lambda+\delta-q] \\
& \lim _{\mathrm{N} \rightarrow \infty} \hat{\mathrm{V}}_{\mathrm{T}-\mathrm{N}}(\mathrm{k})=\hat{\mathrm{V}}(\mathrm{k})=\{\alpha n[\alpha \beta /(1-\alpha \beta)]\} \ln \mathrm{k}+\mathrm{E}
\end{aligned}
$$


where $E$ is a constant.

$$
\begin{aligned}
& \text { Comparing }(18) \text { to (23) gives } \\
& \hat{\theta}_{\mathrm{T}-\mathrm{N}}^{*}(k) \geqslant \hat{\theta}_{\mathrm{T}-\mathbb{N}}(k) \text { for } \mathrm{q}_{\mathbb{N}} \geqslant 0 .
\end{aligned}
$$

Recall that $q_{N}=\Psi+(\beta \alpha)^{N} \alpha \delta-\eta \sum_{j=1}^{N}(\beta \alpha)^{j}$ and that $q_{N}$ converges to $q$. Clearly, $q_{\mathbb{N}}$ is monotone decreasing in $\mathrm{N}$. Depending on parameter values, there are (neglecting inequalities) three possible cases:

- Case 1: $q<\mathrm{q}_{1}<0$

In this case the noncooperative Nash tax rates lie everywhere above the coordinated tax rates and diverge from them. For a graphical representation, see Figures 5 and 6 .

- Case 2: $0<q<q_{1}$

In this case the Nash rates lie everywhere below the coordinated rates and converge toward them. See Figures 7 and 8 .

- Case 3: $q<0<q_{1}$

In this case the Nash rates start below the coordinated rates, cross them, and then lie above them. The Nash rates thus converge to, then diverge from the coordinated rates. See Figures 9 and 10 .

To understand these results, recall that Nash players, being concerned only with their own objective functions, do not take into account the effects their actions have on other players, their transmission effects. In contrast, a world planner does take account of these effects. The planner will increase an action relative to the Nash action if the transmission effect of that action is (globally) positive and decrease it if the effect is negative. 
Recalling the decomposition of effects from the previous section let us consider the results. First, tax rates decrease with the length of the horizon because the longer the horizon the larger the negative effects on future generations. Next, consider the various cases. In Case 1 (when $q<q_{1}$ $(0)$, the negative effects on the future generation dominate the positive effects on the current generation for all horizons. (Notice that even with a horizon of length 1 there is a future one-period-lived generation.) The transmission effect is thus negative, and the Nash rates lie above the coordinated rates. Since the magnitude of the transmission effect increases with the length of the horizon, the Nash rates diverge from the coordinated rates. For Case 2 (when $0<q<q_{1}$ ), the reverse is true. The current generation effects dominate the future generation effects, so the transmission effect is positive, and the Nash rates lie below the coordinated rates. The magnitude of the transmission effect decreases with the length of the horizon, and the Nash rates converge toward the coordinated rates. For Case 3 (when $q$ $\left.<0<q_{1}\right)$, the current generation effects initially outweigh the future generation effects. However, as more future generations are added, the future generation effects eventually dominate. The transmission effect is therefore initially positive, then zero, and finally negative. The Nash rates start below the coordinated rates, then cross them, and finally lie above them.

In summary, the transmission effect is the sum of positive effects on the current generation and negative effects on all future generations; the more that the government cares about future generations and the longer the government's horizon, the larger are these negative effects on future generations and the more likely it is that government spending and tax rates are too high in a Nash equilibrium. 
VI. Equilibrium in a Many-Country World

So far, the analysis has concentrated on a world with two countries. How does the analysis alter as the number of countries gets large? This section shows that increasing the number of countries exacerbates the gaming problems in the sense that the noncooperative policies diverge from the coordinated policies.

Consider a world economy composed of I countries, each of which is identical to the countries described in Section I. The definition of world equilibrium is now the obvious generalization of the two-country case. World equilibrium can be summarized by an equilibrium law of motion for capital, a sequence of tax rates for each country, a set of optimal policy functions for each country's consumers, and a government spending policy for each country. The equilibrium law of motion for capital is

$$
h\left(k_{t}, \theta_{1 t}, \ldots, \theta_{I t}\right)=\delta(1+\delta)^{-1}(1-\alpha)\left(1-\theta_{m t}\right) k_{t}^{\alpha}
$$

where $\theta_{\text {mt }}=\sum_{i=1}^{I} \theta_{i t} / I$ is the world mean tax rate at t. Comparison of (38) and (8) shows that $h\left(k, \theta_{1 t}, \ldots, \theta_{I t}\right)=h\left(k_{t}, \theta_{m t}\right)$; that is, the law of motion for capital in this world economy is identical to that of a closed economy in which tax rates are set equal to the mean world tax rate.

The state of a consumer in country $i$ at time $t$ can be summarized by the world capital stock together with the current taxes on labor in the I countries. To keep symmetry, we will write this state as $\left(k_{t}, \theta_{1 t}, \theta_{-i t}\right)$, where $\theta_{-i t}$ denotes the tax rates of all countries except country $i$ :

$$
\theta_{-i t}=\left(\theta_{1 t}, \ldots, \theta_{i-1, t}, \theta_{i+1, t}, \ldots, \theta_{I t}\right)
$$

The optimal policy functions for a consumer of country $i$ are 


$$
\begin{aligned}
& y\left(k_{t}, \theta_{i t}, \theta_{-i t}\right)=(1-\delta)^{-1}(1-\alpha)\left(1-\theta_{i t}\right) k_{t}^{\alpha} \\
& z\left(k_{t}, \theta_{i t}, \theta_{i t}\right)=\alpha(1-\alpha) \delta(1+\delta)^{-1}\left(1-\theta_{i t}\right) k_{t}^{\alpha} h\left(k_{t}, \theta_{i t}, \theta_{-i t}\right)^{\alpha-1} .
\end{aligned}
$$

The spending policy of the government of country i is

$$
g\left(k_{t}, \theta_{i t}\right)=(1-\alpha) \theta_{i t} k_{t}^{\alpha}
$$

Given any initial capital stocks, (38)-(41) are a set of nonlinear difference equations that completely characterize the equilibrium for any sequence of tax rates $\left\{\theta_{1 t}, \ldots, \theta_{I t}\right\}_{0}^{\infty}$.

The steady-state capital stock can be written

$$
k\left(\theta_{1}, \ldots, \theta_{I}\right)=A\left(1-\theta_{m}\right)^{1 /(1-\alpha)}
$$

From $(46)$ and $(12), k\left(\theta_{1}, \ldots, \theta_{I}\right)=k\left(\theta_{m}\right)$. The tax revenues of country $i$ in a steady state can be written as $\tau\left(\theta_{i}, \theta_{-i}\right)$, where

$$
\tau\left(\theta_{i}, \theta_{-i}\right)=(1-\alpha) A^{\alpha} \theta_{i} w\left[k\left(\theta_{1}, \ldots, \theta_{I}\right)\right]
$$

Now let $\left(\theta_{-i}\right)_{m}$ denote the mean tax rate of all countries except $i$. Since each tax rate lies in a bounded set, as the number of countries gets large the mean tax rate for all countries except $i$ approaches the mean tax rate for all countries:

$$
\left(\theta_{-i}\right)_{m}+\theta_{m} \text { as } I \rightarrow \infty .
$$

In the limit, the mean world tax rate is independent of any one country's tax rate. Because of this, graphs of this world's capital stock and government revenues in Figures 11 and 12 look quite different from Figures 3 and 4. The world capital stock $k\left(\theta_{1}, \ldots, \theta_{I}\right)$ approaches a horizontal line for large $I$, and 
government revenues $\tau\left(\theta_{i}, \theta_{-i}\right)$ approaches a straight line with a slope $w\left[k\left(\theta_{\mathrm{TR}}\right)\right]$ that is independent of $\theta_{i}$.

The analysis of noncooperative and coordinated fiscal policy is the obvious generalization of the analysis in sections IV and $V$. If we let $\theta_{\mathrm{T}-\mathrm{N}}^{*}(k ; I)$ denote the symmetric Nash equilibrium to the stage $N$ game with I players, then we can show

$$
\theta_{T-N}^{*}(k ; I)=\lambda /\left[1+\lambda+\delta-\left(q_{N} / I\right)\right]
$$

As the horizon tends to infinity, these functions converge to a limit denoted $\pi^{*}(\mathrm{k} ; \mathrm{I})$ :

$$
\lim _{\mathbb{N} \rightarrow \infty} \theta_{T-\mathbb{N}}^{*}(k ; I)=\theta^{*}(k ; I)=\lambda /[1+\lambda+\delta-(q / I)] \text {. }
$$

Thus $\theta^{*}(k, I)$ is a syrmetric sequential Nash equilibrium for the infinite horizon game with I players. In (45) notice that, as the number of players increases, the sequential Nash equilibrium tax rates increase (decrease) if $q$ is negative (positive). As the number of players tends to infinity, the equilibrium strategies for the infinite horizon game converge to $\theta^{*}(k)$ :

$$
\lim _{I \rightarrow \infty} \theta^{*}(k ; I)=\theta^{*}(k)=\lambda /(1+\lambda+\delta)
$$

For the coordinated case, let $\hat{\theta}_{\mathrm{T}-\mathrm{N}}(k ; I)$ denote the optimal fiscal policy at stage $\mathrm{T}-\mathrm{N}$ given I countries. Then

$$
\hat{\theta}_{N}(k ; I)=\lambda /\left[1+\lambda+\delta-q_{N}\right]
$$

As the horizon tends to infinity, this optimal policy converges to $\hat{\theta}(k ; I)$ :

$$
\lim _{N \rightarrow \infty} \hat{\theta}_{N}(k ; I)=\hat{\theta}(k ; I)=\lambda /[1+\lambda+\delta-q]
$$


Notice that the optimal fiscal policy is independent of the number of countries at each stage and in the limit. In particular, if $\hat{\theta}(k)$ denotes the optimal fiscal policy in the infinite horizon case with an infinite number of countries, then $\hat{\theta}(k)=\hat{\theta}(k ; I)$ for each $I$.

Comparison of (45) and (47) shows that the optimal fiscal policy under coordination is lower (higher) than the sequential Nash policy if $q$ is negative (positive). The comparison also shows that, if $q$ is negative, the ratio of the sequential Nash tax rates to the optimal tax rates increases as the number of countries increases:

$$
1<\frac{\theta^{*}(k ; 2)}{\hat{\theta}(k ; 2)}<\frac{\theta^{*}(k ; 3)}{\hat{\theta}(k ; 3)}<\ldots<\frac{\theta^{*}(k ; I)}{\hat{\theta}(k ; I)}<\ldots<\frac{\theta^{*}(k)}{\hat{\theta}(k)} .
$$

If $q$ is positive, the ratio decreases with the number of countries and the inequalities in (49) are reversed. In either case, as the number of countries increases the Nash rates diverge from the coordinated rates.

To understand these results, consider how an increase in any one country's tax rates--say, country j's--affects the welfare of each country as well as that of the world planner. The effect of an increase in country $j$ 's tax rate at $T-N$ on any other country $i$ 's welfare, for $i \neq j$, is

$$
\partial R_{i, T-N} / \partial \theta_{j, T-N}=q_{N} / I\left(1-\theta_{m, T-N}\right)
$$

This is just the many-country version of the transmission effect of the last section. Any increase in some country's tax rate affects the welfare of all other countries' current and future generations by reducing the world capital stock. The larger the number of countries, the smaller the change in the world capital stock and thus the smaller the transmission effect to any one country. 
The effect of an increase in country $j^{\prime} s$ tax rate at $T-N$ on its own welfare is

$$
\begin{aligned}
\partial R_{j, T-N} / \partial \theta_{j, T-N}= & {\left[(1+\delta) /\left(1-\theta_{j, T-N}\right)+\lambda / \theta_{j, T-N}\right] } \\
& +\left[q_{N} / I\left(1-\theta_{m, T-N}\right)\right] .
\end{aligned}
$$

Call the first term in brackets the direct effect; for a given level of the capital stock, higher taxes affect only the current generation by reducing wages and increasing government spending. Notice that this effect does not depend on the number of countries. The second term in brackets is the indirect capital stock effect; an increase in country j's tax rate also reduces the world capital stock and thus affects its own current and future generations. This indirect capital stock effect is, of course, identical to the above transmission effect since a change in the world capital stock affects all countries symmetrically.

Finally, the effect of an increase in country $j^{\prime} s$ tax rate on the planner's objective function is just the sum of the above effects; that is,

$$
\begin{aligned}
\partial R_{T-N} / \partial \theta_{j, T-N} & =\sum_{i=1}^{T} \partial R_{i, T-N} / \partial \theta_{j, T-N} \\
& =\left[(1+\delta) /\left(1-\theta_{j, T-N}\right)+\lambda / \theta_{j, T-N}\right]+q_{N} /\left(1-\theta_{m, T-N}\right) .
\end{aligned}
$$

Now consider how the objective of a Nash player differs from that of a planner. On the one hand, country $j$ acting as a Nash player chooses its tax policy, given other players' policies, to balance the direct effects on itself with the indirect effects on itself. As the number of countries increases, the size of the direct effects stays constant while that of the indirect effects diminishes. If $\mathrm{q}_{\mathrm{N}}$ is positive, these indirect effects are beneficial, 
and as they diminish the Nash tax rates increase. If $\mathrm{q}_{\mathrm{N}}$ is negative, these indirect effects are harmful, and as they diminish the Nash tax rates decrease. On the other hand, the planner chooses tax rates of, say, country $j$ to balance the direct effects on country $j$ with the sum of the indirect effects on all countries. As the number of countries increases, not only the direct effects stay constant; the sum of the indirect effects does too, so the coordinated rates do not vary with the number of countries.

Now if $q_{N}$ is negative, the transmission effect is negative, and the Nash rates lie above the coordinated rates. As the number of countries increases, the Nash rates increase, the coordinated rates stay constant, and the Nash rates diverge from the coordinated rates. If $q_{\mathbb{N}}$ is positive, the transmission effect is positive, and the Nash rates lie below the coordinated rates. As the number of countries increases, the Nash rates decrease, the coordinated rates stay constant, and the Nash rates again diverge from the coordinated rates.

VII. Conclusion

In sumary, this paper presents a simple example which shows that as each country's economy becomes small relative to the world economy, the gaming problems involved in policy setting get worse. This result emerges from a model that abstracts from those features that give rise to time inconsistency problems (of the type analyzed, for example, in Rogoff [1985] and Kehoe [1986]). The model also uses the most common parametric utility and production functions. This suggests that the intuition developed in the optimal tariff literature--in which gaming problems disappear as each country's economy becomes small--does not, in general, apply to other types of government policy. 
In addition, this paper shows that, because of the deleterious effects current high government spending has on future generations, without coordination there may be a tendency for government spending to be too high. In such a case, it would be optimal to engineer a joint contraction in the size of government spending. Of course, I do not mean to claim that such a joint contraction should necessarily be undertaken, rather I have concentrated on a simple model that points out some of the forces that would lead to such a conclusion. In this sense, the paper can be viewed as complementary to standard Keynesian analyses which, because of their short-run perspective, tend to concentrate on forces that lead to the opposite conclusion--that countries should coordinate to expand government spending.

Let me conclude with a suggestion for some empirical work. In a recent study, Sachs and Oudiz (1984) empirically estimated the gains from coordination in a simple Keynesian model. Their main result was that the gains from coordination are very small. Loosely speaking, in their theoretical model the gains from coordination are directly proportional to the size of the transmission effects of policy (as measured by bilateral trade multipliers). In the data, these transmission effects are small and thus the gains from coordination are small. Notice that the model of this paper works quite differently: the gains from coordination are inversely proportional to the size of the transmission effect (of any one country on another). In particular, the gains from coordination are greatest when these bilateral transmission effects are zero. This suggests that if one built an empirical model based on an intertemporal public finance perspective, one might, perhaps, reach a very different conclusion about the size of the gains from coordination. 
Notes

1/It is well-known that either of these render optimal policies time inconsistent [see Kydland and Prescott (1980) and Lucas and Stokey (1983)] at least for a broad class of models which includes the one considered here.

It is also true that when optimal policies are time inconsistent it is possible to obtain other even more striking results. For example, one may imagine it trivial to show that coordination by policymakers always leads to more desirable allocations. The line of argument is that coordinating policymakers can always do at least as well as if they were not cooperating simply by choosing their noncooperative strategies. This simple argument is fallacious, of course, since it neglects the fact that other players--here, private agents--may change their strategies in such a way that the noncooperative allocation is not an equilibrium. This is true even when private agents are small. Rogoff (1985) shows that, in a Keynesian context, sequential coordination can lead to an outcome inferior to the noncooperative outcome. Kehoe (1986) provides a simple example illustrating Rogoff's point in an equilibrium context, using Fischer's (1980) optimal tax example of time inconsistency. The basic idea is that sequential coordination leads to the no commitment (time consistent) solution. Noncooperation, however, acts like partial commitment and hence improves matters.

$2 /$ These functional forms are some of the few that, like the quadratic functional forms, give closed form decision rules. Because of this, many analyses have used them. In nonstrategic settings, they have been used by Radner (1966), Brock and Mirman (1972), Long and Plosser (1983), and others; in a strategic setting, they have been used by Levhari and Mirman (1980). Much of the algebra in later sections of the current paper parallels that in these papers, especially that in Levhari and Mirman's (1980). 
3/The function $k(\theta)$ has these properties:

$$
\begin{aligned}
& \mathrm{k}(0)=\mathrm{A}, \mathrm{k}(1)=0 \\
& \mathrm{k}_{\theta}(\theta)=-\mathrm{A}(1-\theta) \alpha /(1-\alpha) /(1-\alpha) \\
& \mathrm{k}_{\theta}(0)=-A /(1-\alpha), \mathrm{k}_{\theta}(1)=0 \\
& \mathrm{k}_{\theta \theta}(\theta)=\alpha A(1-\theta)(2 \alpha-1) /(1-\alpha) /(1-\alpha)>0
\end{aligned}
$$

where $k_{\theta}(\theta)=\partial k(\theta) / \partial \theta$ and $k_{\theta \theta}(\theta)=\partial^{2} k(\theta) / \partial \theta^{2}$.

4/The function $\tau(\theta)$ has these properties:

$$
\begin{aligned}
& \tau(0)=0, \tau(1)=0 \\
& \tau_{\theta}(\theta)=\alpha A{ }^{\alpha}(1-\theta)^{\alpha /(1-\alpha)}\left[\frac{1-\alpha}{\alpha}-\frac{\theta}{1-\theta}\right]
\end{aligned}
$$

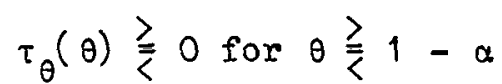

$$
\begin{aligned}
& \tau_{\theta}(0)=(1-\alpha) A^{\alpha}, \lim _{\theta \rightarrow 1} \tau_{\theta}(\theta)=-\infty .
\end{aligned}
$$

$5 /$ The function $k\left(\theta_{1}, \theta_{2}\right)$ has these properties:

$$
\begin{aligned}
& \mathrm{k}\left(0, \theta_{2}\right)=\mathrm{A}\left(1-\theta_{2} / 2\right)^{1 /(1-\alpha)}, \mathrm{k}\left(1, \theta_{2}\right)=\mathrm{A}\left(1 / 2-\theta_{2}\right)^{1 /(1-\alpha)} \\
& \mathrm{k}_{\theta_{1}}\left(\theta_{1}, \theta_{2}\right)=-\mathrm{A}\left(1-\theta_{\mathrm{m}}\right)^{\alpha /(1-\alpha)} /[2(1-\alpha)] \\
& \mathrm{k}_{\theta_{1}}\left(0, \theta_{2}\right)=-\mathrm{A}\left(1-\theta_{2} / 2\right)^{\alpha /(1-\alpha)} /[2(1-\alpha)] \\
& \mathrm{k}_{\theta_{1}}\left(1, \theta_{2}\right)=-\mathrm{A}\left(1 / 2-\theta_{2} / 2\right)^{\alpha /(1-\alpha) /[2(1-\alpha)]} \\
& \mathrm{k}_{\theta_{1} \theta_{1}}\left(\theta_{1}, \theta_{2}\right)=\alpha A\left(1-\theta_{m}\right)^{\alpha /(1-\alpha) /[4(1-\alpha)]>0 .}
\end{aligned}
$$


$6 /$ The function $\tau\left(\theta_{1}, \theta_{2}\right)$ has these properties:

$$
\begin{aligned}
& \tau\left(0, \theta_{2}\right)=0, \tau\left(1, \theta_{2}\right)=\alpha A^{\alpha\left(1 / 2-\theta_{2} / 2\right) \alpha /(1-\alpha)} \\
& \tau_{\theta_{1}}\left(\theta_{1}, \theta_{2}\right)=\alpha A^{\alpha}\left(1-\theta_{m}\right)^{\alpha /(1-\alpha)}\left[\frac{1-\alpha}{\alpha}-\frac{\theta_{1}}{2-\theta_{1}-\theta_{2}}\right] \\
& \tau_{\theta_{1}}\left(\theta_{1}, \theta_{2}\right) \leqq 0 \text { for } \theta_{1} \gtreqless 2(1-\alpha)\left(1-\theta_{2} / 2\right) \\
& \tau_{\theta_{1}}\left(0, \theta_{2}\right)=(1-\alpha) A^{\alpha}\left(1-\theta_{2} / 2\right)>0 \\
& \tau_{\theta_{1}}\left(1, \theta_{2}\right)=A^{\alpha}\left[(1-\alpha)\left(1-\theta_{2}\right)-1\right] / 2<0 \\
& \tau\left(\theta_{1}, \theta_{2}\right) \gtreqless \tau\left(\theta_{1}\right) \text { for } \theta_{2} \leqq \theta_{1} \cdot
\end{aligned}
$$

I/See Prescott and Townsend (1980). Levhari and Mirman (1980) use the term "dynamic Cournot-Nash equilibrium" for a similar concept. Prescott and Townsend's (1980) term "sequential Nash equilibrium" should not be confused with Kreps and Wilson's (1982) term "sequential equilibrium."

In addition, a large number of equilibrium concepts in control theory, macroeconomic theory, and game theory are closely associated with the one analyzed here. This particular concept was adopted both because it seemed to be appropriate for this application and because it was convenient.

8/To see that this solution is time consistent consider another type of coordination in which there is only one world planner who sets a sequence of tax functions for each country once and for all at time 0 . The problem of such a planner is to choose $\left\{\theta_{1 t}\left(k_{t}\right), \theta_{2 t}\left(k_{t}\right)\right\}_{0}^{\infty}$ to maximize

$$
\sum_{t=0}^{\infty} \beta^{t}\left[U\left(k_{t}, \theta_{1 t}, \theta_{2 t}\right)+U\left(k_{t}, \theta_{2 t}, \theta_{1 t}\right)\right] / 2
$$

subject to 
$k_{t+1}=h\left(k_{t}, \theta_{1 t}, \theta_{2 t}\right)$

$k_{0}$ given.

Assuming symmetric treatment, the solution to this problem coincides with the solution to the problem under the other type of coordination. That is, there no time inconsistency of date 0 plans since this is a dynamic programming problem. In particular, the current return and the transition equation do not depend on future controls. (For details, see Sargent, forthcoming; Stutzer 1984; and Appendix B of this paper.) 
Appendix A

This appendix computes the symmetric sequential Nash equilibrium for the two country model using an algorithm similar to the one in Levhari and Mirman (1980).

Consider first the stage $T$. game. The government of country 1

solves

$\max \mathrm{R}_{1 \mathrm{~T}}\left[\mathrm{k}, \theta_{1}, \theta_{2 \mathrm{~T}}(\mathrm{k})\right]=\ln \left[\left(1-\theta_{1}\right) \mathrm{w}(\mathrm{k})\right]+\lambda \ln \left[\theta_{1} \mathrm{w}(\mathrm{k})\right]$.

Since the objective function for the final government of country 1 does not depend on the choice of the final government of country 2 and vice versa, the Nash equilibrium to the stage $T$ game is trivially computed to be

$$
\theta_{T}^{*}(k)=\lambda /(1+\lambda)
$$

Notice that for this parametric structure the Nash strategies turn out to be constant across capital-labor ratios. Substituting this strategy into the objective function gives

$$
V_{T}^{*}(k)=R_{1 T}\left[k, \theta_{T}^{*}(k), \theta_{T}^{*}(k)\right]=\alpha(1+\lambda) \ln k+D_{T}
$$

where $D_{T}$ is a constant that does not affect the choice of tax rates. Consider next the stage T - 1 game. The government of country 1 solves

$$
\begin{aligned}
\max _{\theta_{1}} \mathrm{R}_{1, \mathrm{~T}-1}\left[\mathrm{k}, \theta_{1}, \theta_{2, \mathrm{~T}-1}(\mathrm{k})\right]= & \mathrm{U}\left[\mathrm{k}, \theta_{1}, \theta_{2, \mathrm{~T}-1}(\mathrm{k})\right] \\
& +B \mathrm{~V}_{\mathrm{T}}^{*}\left[\mathrm{~h}\left(\mathrm{k}, \theta_{1}, \theta_{2, \mathrm{~T}-1}(\mathrm{k})\right)\right] .
\end{aligned}
$$

Using (12), (13), and (14), we can rewrite this as

$$
\max _{\theta_{1}}(1+\delta) \ln \left[1-\theta_{1}\right]-\Psi \ln \left[1-\left(\theta_{1}+\theta_{2, T-1}(k)\right) / 2\right]+\lambda \ln \theta_{1}
$$




$$
+\alpha \eta \ln k+\beta \alpha(1+\lambda) \text { In }\left[1-\left(\theta_{1}+\theta_{2, T-1}(k) / 2\right) k_{T}^{\alpha}\right]+A_{T-1}
$$

where $\Psi=(1-\alpha) \delta, n=1+\lambda+\alpha \delta$, and $A_{\Gamma-1}$ is an unimportant constant. The first-order condition is

$$
\frac{1+\delta}{1-\theta_{1}}+\frac{[\beta \alpha(1+\lambda)-\Psi] / 2}{1-\left[\theta_{1}+\theta_{2, T-1}(\mathrm{k})\right] / 2}=\frac{\lambda}{\theta_{1}} .
$$

The first-order condition for country 2 is symmetric. The unique symetric Nash equilibrium to the stage $T-1$ game is

$$
\theta_{\mathrm{T}-1}^{*}(k)=\lambda /\left[1+\lambda+\delta-\left(q_{1} / 2\right)\right]
$$

where $q_{1}=\Psi+(\beta \alpha)(\alpha \delta)-n(\beta \alpha)$. Substituting the policy function into the objective function gives

$$
\mathrm{V}_{\mathrm{T}-1}^{*}(\mathrm{k})=\left[\alpha,(1+\beta \alpha)-(\beta \alpha) \alpha^{2} \delta\right] \text { In } \mathrm{k}+\mathrm{D}_{\mathrm{T}-1}
$$

where $D_{\mathrm{T}-1}$ is an unimportant constant. Continuing in the same manner gives, after $\mathrm{N}$ steps,

$$
\begin{aligned}
& \theta_{\mathrm{T}-\mathrm{N}}^{*}(\mathrm{k})=\lambda /\left[1+\lambda+\delta-\left(q_{\mathrm{N}} / 2\right)\right] \\
& \mathrm{V}_{\mathrm{T}-\mathrm{N}}^{*}(\mathrm{k})=\left[a \sum_{j=0}^{N}(\beta \alpha)^{j}-(\beta \alpha)^{\mathrm{N}} \alpha^{2} \delta\right] \ln \mathrm{k}+\mathrm{D}_{\mathrm{T}-\mathrm{N}}
\end{aligned}
$$

where $q_{\mathbb{N}}=\Psi+(\beta \alpha)^{\mathbb{N}} \alpha \delta-n \sum \sum_{j=1}^{\mathbb{N}}(\beta \alpha)^{j}$. As the horizon tends to infinity, the Nash equilibrium strategies and the value functions converge to $\theta^{*}(k)$ and $\mathrm{V}^{*}(\mathrm{k})$, respectively:

$$
\begin{aligned}
& \lim _{N \rightarrow \infty} \theta_{T-N}^{*}(k)=\theta^{*}(k)=\lambda /[1+\lambda+\delta-(q / 2)] \\
& \lim _{N \rightarrow \infty} V_{T-N}^{*}(k)=V^{*}(k)=[\alpha N /(1-\beta \alpha)] \ln k+D
\end{aligned}
$$


where $q=\Psi-\eta \beta \alpha /(1-\beta \alpha)$. Now the pair $\{\theta(k), \theta(k)\}$ is defined to be the symmetric sequential Nash equilibrium for the infinite horizon game. 
Appendix B

In the preceding paper, the benefits of the public good accrue only to the young. Here we consider the case where the public good benefits both the young and the old. In particular, let a generation $t$ consumer of country i now have this utility function:

$$
\begin{aligned}
& u\left(y_{i t}, z_{i}, t+1, g_{i t, t+1}\right)=\left[\ln y_{i t}+\lambda_{1} \text { ln } g_{i t}\right] \\
& +\delta\left[\ln z_{i, t+1}+\lambda_{2} \ln g_{i, t+1}\right] \text {. }
\end{aligned}
$$

The analysis of Sections II and III is unchanged in the case. However, a slight change is needed in the objective function of the time $t$ governments and planners to keep the analysis parallel to the paper's later sections.

In the paper, the objective functions of the time $t$ governments and planner are defined as the discounted value of utility of all generations $t$ and after. Section $V$ shows that sequential coordination coincides with date 0 coordination, that is, that given the definition of period returns the problem of the planner is a dynamic programming problem. If individuals now have the above utility function and the period return is defined as before, the sequential solution will not coincide with the date o solution. Basically, this arises because the planner's current return depends on future controls. However, in this case the appropriate way to write the problem in dynamic programming form is to define the planner's return at $t$ to be the discounted value of all generations $t-1$ and earlier. With the returns so defined, the sequential solution will coincide with the date 0 solution and the date 0 problem will be a dynamic programing problem. Without this modification, for the above objective function, the time $t$ planner would not take into account 
the effects that current government spending has on the current old and so would set taxes and spending too. low relative to the date 0 problem. With the previous utility functions, the planner at $t$ has no effect on generations $t$ 1 and earlier, and either definition of period returns gives the same answer. With this modification, the various tax policies are the same as in the text if $\lambda$ is replaced by $\lambda_{1}+\delta \lambda_{2} / \beta$. There are two basic differences in the subsequent analysis. First, the indirect effects on the current generation of a change in current taxes include, in addition to the interest rate effect, a type of wage effect. Higher current taxes decrease next period's wage, which decreases the amount of public goods consumed by the current generation when old. Second, the wage effect for future generations is stronger. A lower capital stock decreases wages, which decreases the amount of public good consumption by the old of every future generation. Both of these effects increase the likelihood that the transmission effect is negative.

Note that Calvo and Obstfeld (1985) have analyzed, in a more complicated setup, some of the issues discussed in this Appendix. 
References

Brock, William A., and Mirman, Leonard J. "Optimal Economic Growth And Uncertainty: The Discounted Case." Journal of Economic Theory 4 (June 1972): $479-513$.

Calvo, Guillermo A. "Capital Accumulation and Welfare: A Note." Economics Letters 4, no. 2 (1979): 135-39.

Calvo, Guillermo A., and Obstfeld, Maurice. "Optimal Time-Consistent Fiscal Policy with Uncertain Lifetimes." Working Paper 1593. Cambridge, Mass.: National Bureau of Economic Research, 1985.

Cooper, Richard N. "Economic Interdependence and Coordination of Economic Policies." In Handbook of International Economics, vol. 2, edited by Ronald W. Jones and Peter B. Kenen, pp. 1195-1234. Amsterdam: NorthHolland, 1985.

Diamond, Peter A. "National Debt in a Neoclassical Growth Model." American Economic Review 55, no. 5, pt. 1 (December 1965): 1126-50.

Fischer, Stanley. "Dynamic Inconsistency, Cooperation and the Benevolent Dissembling Government." Journal of Economic Dynamics and Control 2 (February 1980): 93-107.

Green, Edward J. "Non-cooperative Games and Equilibrium Market Strategies." Ph.D. dissertation, Carnegie-Mellon University, 1977. Hamada, Koichi. "A Strategic Analysis of Monetary Interdependence." Journal of Political Economy 84, no. 4, pt. 1 (August 1976): 677-700.

Kehoe, Patrick J. "Fiscal Financing in a Non-Ricardian World Economy." Manuscript. Minneapolis: University of Minnesota, 1984.

- "International Policy Cooperation May be Undesirable." Research Department Working Paper 290. Minneapolis: Federal Reserve Bank of Minneapolis, 1986. 
Kreps, David M., and Wilson, Robert. "Sequential Equilibria." Econometrica 50, no. 4 (July 1982): 863-94.

Kydland, Finn E., and Prescott, Edward C. "Rules Rather Than Discretion: The Inconsistency of Optimal Plans." Journal of Political Economy 85 (June 1977): 473-91:

- "Dynamic Optimal Taxation, Rational Expectations and Optimal Control." Journal of Economic Dynamics and Control 2 (February 1980): $79-91$.

Eevhari, David, and Mirman, Leonard J. "The Great Fish War: An Fxample Using a Dynamic Cournot-Nash Solution." Bell Journal of Economics 11, no. 1 (Spring 1980): $322-34$.

Long, John B., Jr., and Plosser, Charles I. "Real Business Cycles." Journal of Political Economy 91 (February 1983): 39-69.

Lucas, Robert E. Jr., and Stokey, Nancy I. "Optimal Fiscal and Monetary Policy on a Model Without Capital." Journal of Monetary Economics 12, no. 1 (July 1983): 55-93

Miller, Preston, and Wallace, Neil. "National Monetary Policies in a World Economy: A Role for Cooperation." Research Department Working Paper 268. Minneapolis: Federal Reserve Bank of Minneapolis, 1985. Also available as "International Coordination of Macroeconomic Policies: A Welfare Analysis." Federal Reserve Bank of Minneapolis Quarterly Review 9 (Spring 1985): 14-32.

Prescott, Edward C., and Townsend, Robert M. "Equilibrium under Uncertainty: Multiagent Statistical Decision Theory." In Bayesian Analysis in Econometrics and Statistics: Essays in Honor of Harold Jeffreys, edited by Arnold Zeliner, pp. 169-94. Amsterdam: North-Holland, 1980. 
Radner, Roy. "Optimal Growth in a Linear-Logarithmic Economy." International Economic Review 7 (January 1966): $1-33$.

Rogoff, Kenneth. "Can International Monetary Policy Cooperation be Counterproductive?" Journal of International Economics 18, no. 3/4 (May 1985): $199-217$.

Sargent, Thomas J. Dynamic Macroeconomic Theory. Cambridge, Mass.: Harvard University Press, forthcoming.

Sachs, Jeffrey, and Oudiz, Gilles. "Macroeconomic Policy Coordination Among Industrial Countries." Brookings Papers on Economic Activity Vol. 2, $1984,1-64$.

Sebastian, Miguel. "Fixed Bxchange Rates and Non-Cooperative Monetary Policies." Manuscript. Minneapolis: University of Minnesota, 1985.

Stutzer, Michael J. "Time Consistency of Optimal Plans: An Elementary Primer." Research Department Staff Report 91. Minneapolis: Federal Reserve Bank of Minneapolis, 1984. 